\title{
How Does Social Media Affect the Behaviours of Managers and Employees in Non-Democratic Countries?
}

\section{Ali Fathi Makvand and Vicenc Fernandez}

\begin{abstract}
The majority of social media studies have focused their attention on national and international companies in developed countries where democracy is part of the national culture of their citizens. The purpose of this research is to understand how social media usage effects organizational behaviour and culture in non-democratic countries. From a qualitative framework based on the current literature and Hofstede cultural analysis, we developed semi-structured interviews with one CEO and five middle managers from an international company in Iran in order to suggest several ways on how the use of social media within this type of company affects organizational behaviour. The results indicate that organizational culture is influenced by culture in nondemocratic countries. The use of social media also has a positive impact on transformational leadership, collaboration, knowledge sharing and team-work but negatively on transparency which increases organizational stress.
\end{abstract}

Keywords: Social Media, Non-Democratic Countries, Organizational Behaviour, Culture.

\subsection{Introduction}

Social media is considered as an effective tool which enables stakeholders and external and internal entities to communicate and collaborate to create governance (Georgescu \& Popescul, 2015). Organizations in developing countries faced challenges with the rise of social media use (Danju, Maasoglu, \& Maasoglu, 2013; Ghannam, 2011; Kneissl, 2011). They encountered a transforming society and surroundings where employees have used social media networks on a massive scale (Gil de Zúñiga, Jung, \& Valenzuela, 2012; Taki \& Coretti, 2013). In addition, the competitive environment forces organizations to present numerous social media channels to meet their needs (Schiuma, Vuori, \& Okkonen, 2012). However, many organizations and industries find easily positioning social 
media strategies in accordance with their organizational culture, but companies often struggle to adopt social media usage in accordance with their organizational culture in non-democratic countries (Silverthorne, 2004; Taki \& Coretti, 2013; Zukin, Keeter, Andolina, Jenkins, \& Carpini, 2006).

Country culture is stronger than an organizational one in non-democratic countries Hofstede (1994); Silverthorne (2004); however, the advent of social media inside of organizations and recent uprisings in countries located in the Middle East and North Africa recruited managers to redefine their organizational culture based on new forms of management context (MacIntosh \& Doherty, 2010; Silverthorne, 2004; Taki \& Coretti, 2013). Organizational resistance towards the use of social media increases in organizations by leaders and managers in such countries while social media tools become more popular among employees to share their ideas and knowledge (Burke, 1994; Danju et al., 2013). By the way, the culture capability of such countries to accept these changes, impacts on organizational goals (Ghannam, 2011; Gil de Zúñiga et al., 2012).

There is an extensive acknowledgment of the potential of social media tools for achieving social and civic outcomes in developed countries (e.g. Johns, 2014; Parveen et al., 2014; Razmerita et al., 2014), but there few studies to understand how and why these tools impact society and companies in developing countries. For many years, social media was just considered by Western countries to carry on their business strategies (Danju et al., 2013). However, recent uprisings in Arab countries have been transforming the adoption of social media in different areas of society in the Middle East and North Africa. This fact has accelerated the democratization in autocratic countries (Auger, 2013; Danju et al., 2013; Ghannam, 2011; Kneiss1, 2011).

Industries and companies are being influenced by this transformation as part of society in developing countries (Auger, 2013; Taki \& Coretti, 2013). However, the lack of culture capabilities in such countries creates different impacts on organizations (Auger, 2013). This paper tries to answer the following research question: What positive and negative impact does the use of social media have in the organizational culture of a company in a country without democratic national culture?

In order to answer the research question, we established a model based on the existing literature review and the Hofstede cultural analysis (Hofstede, 1994). We also carried out a qualitative research with an inductive 
approach where the interview of one CEO and five middle managers from an international company in Iran were the main source of gathered data. After coding and analyzing all gathered data, we propose to demonstrate where the main effects of the use of social media impacts on leadership context, organizational culture and organizational behavior in companies in a non-democratic country.

\subsection{Literature Review}

New schemes of social media have changed the way in which individuals communicate and share information (Ellison et al., 2007). According to Kaplan and Haenlein (2010), social media tools are the new era of webenabled applications that engage people to participate in and (co-)create content. Schiuma et al. (2012) suggest social media builds a wide variety of formats such as Social Network Sites (Facebook, Twitter and Instagram), Wikis, Blogs and Podcasts, which also enable individuals to share information by a variety of content formats such as text, videos, graphs, pictures, audios and PDF through the internet (Jin, 2013).

Social media is taking an important role in an individual and collective involvement of citizens in addressing social issues (i.e. civic engagement) (Gil de Zúñiga et al., 2012; Zukin et al., 2006). This fact is because social media allows anyone to spread social causes and to participate with few resources and a little knowledge of technology (Warren, Sulaiman, \& Jaafar, 2014). In other words, citizens are empowered with social tools to force people, particularly the government, to listen to what they care about (Warren et al., 2014) from a community to world issues in order to change perspectives and even policies (Gil de Zúñiga et al., 2012; Warren et al., 2014).

Social media have had a particularly sharp impact on the Middle East and North Africa (Danju et al., 2013; Ghannam, 2011; Kneissl, 2011), where citizens have been able to circumvent censorship (Danju et al., 2013), to build communities of dissent (Ghannam, 2011) and build a new identity (Kneissl, 2011). Social media networks contributed significantly to the wave of uprisings known as Arab Spring (Danju et al., 2013; Ghannam, 2011; Taki \& Coretti, 2013). In a short period of time, a number of North African and Middle Eastern countries have moved from authoritarian regimes as a starting point though a democratic change (Danju et al., 2013; Poorkarimi et al., 2013).

Auger (2013), Kneissl (2011) and Ghannam (2011) argue that the extensive use of social media networking has an elective empathy with 
democratization. Ghannam (2011) and Auger (2013) state that millions of young people utilized social media as a tool of communication to start the Arab Spring, not as the main tool of the revolution (Shirky, 2011), but as a catalyser to represent public opinion and awareness (Auger, 2013; Danju et al., 2013). These social movements have highlighted the importance of social media in energizing political participation in non-democratic countries (Auger, 2013; Danju et al., 2013; Ghannam, 2011; Kneissl, 2011; Taki \& Coretti, 2013).

As the impact of social media networking on Arab Spring, people in nondemocratic countries (e.g. Egypt, Libya, Bahrain, Jordan, and Syria) have taken matters into their own hands in order to get rid of corrupt and autocratic politics (Danju et al., 2013; Ghannam, 2011). For many years, social media was just related to North America and Europe (Auger, 2013; Gil de Zúñiga et al., 2012; Warren et al., 2014); however, the Arab Spring have dramatically changed the adoption of social media in the Middle East and North Africa (Ghannam, 2011; Kneissl, 2011). People in nondemocratic countries are using social media to experience democratic society (Kneissl, 2011; Taki \& Coretti, 2013).

Social media and networking by themselves do not presently propel to enhance democratization (Keser, Uzunboylu, \& Ozdamli, 2011). There is a high tendency for controlling social media by a few groups of communities, companies, governments, and even individuals in nondemocratic countries and this makes barriers to the ambitions of those looking for democratization (Auger, 2013; Kneissl, 2011). Moreover, a new problem appears, because the idea of democracy as declared in Tunisian, Syrian, Libyan and Egyptian revolts, has different points of view and interpretations, confusing many people although all come from the same original source (Keser et al., 2011).

Hofstede (1994) defines culture in specifying organizational members from others by the common and exclusive programming of the mind which refers to the values, heroes, symbols and rituals. Cultures present in numerous kinds of layers such as national culture as a large collective culture, organizational culture, and at the smaller coordinate: organizational subcultures and occupational cultures (Hofstede, 1994; McSweeney, 2002; Minkov and Hofstede, 2012). Based on the research topic, we focus on the impact of national culture, and on organizational culture in the related country context. Therefore we explore the Hofstede's dimension framework to further break down how organizational cultures are usually influenced by country culture. 
Culture builds a direction for people, organizations and countries based on how they behave and think. Hofstede provided four dimensions that culturally impact on a workplace: 1) masculinity/femininity 2) uncertainty avoidance 3) power distance, 4) individualism/collectivism (Hofstede, 1994).

Feminine culture mostly focuses on values such as high lifestyle quality and uniqueness is not valued while in a masculine culture, performance career and success in society are the most important values (Hofstede, 1994).

Uncertainty avoidance refers to how individuals and group members react to ambiguous situations. Cultures with a low score in uncertainty avoidance like Canada would like to take more risk to create innovations. In contrast, those cultures with high uncertainty avoidance like Great Britain would prefer to make trusting regulations to avoid risk. Organizations in this culture make a large number of rules to avoid employees' deviance towards organizational policies (Hofstede, 1994).

Power distance refers to the inequality in power distribution between superiors. It reveals the degree of dependency associations in a country. The fact is a higher degree in power distance shows a tendency towards a hierarchical system. For example, Arab countries are higher on the power distance whilst the United States demonstrate a lower degree in power distance by adoption of participative management that builds more equal terms between superiors and subordinates (Hofstede, 1994).

Individualism and collectivism refer to self-oriented people from a culture collectivists are working in group harmony to make common goals such as Asian countries which adhere to more common principles while individualism are mostly focusing on their own achievement and interest. The United States is evaluated as the highest individualistic culture (Hofstede, 1994).

These movements in non-democratic countries have had important effects in the national culture of these countries (Keser et al., 2011). Due to the fact that the national culture and organizational culture are linked, there are some researchers who have focused on the impact of using social media in organizational cultures, (e.g. Adler \& Gundersen, 2007; Gregory, Harris, Armenakis, \& Shook, 2009) but without distinguishing between companies in democratic and non-democratic countries. Barney (1986) explains a culture as a set of standards, values, and beliefs and the ways staffs behave that make an idiosyncratic feature to organizations jointly 
which effectively accomplish organization goals; in fact, it delivers indexes for organizational processes and events with figuring ethical forms for workers' job and behavior. Schein (1990) suggests organizational culture as a scheme of common fundamental suppositions that staffs and employees can create, realize, and improve to manage with the difficulties of outside adaptations and inside incorporation.

According to Schein (1990), organizational culture involves of three key roles: (1) it supports workers to care about the organization running; (2) it is a profoundly surrounded pattern of social control and (3) it is also links individuals together and adheres them with the organizational development (McShane \& Travaglione, 2007). Moreover, it possesses on shaping and adapting an organization due the change in social and industry developments over a period of time along with behaviour integration of staffs (Hatch \& Schultz, 2004; McShane \& Travaglione, 2007; Schein, 1990). Therefore, it could be considered that organizational culture recognizes the approaches in which an organization works and how the staffs shape occurrences internally and externally for the organization (Ardichvili, Maurer, Li, Wentling, \& Stuedemann, 2006).

The national culture and organizational culture both exert powerful influences on people (Adler \& Gundersen, 2007; Gregory et al., 2009). It is difficult for employees, especially those who are working for foreign companies, facing conflicts between these two kinds of cultures (Gregory et al., 2009). Organizational culture is mainly informal while a national culture is more formal (Gregory et al., 2009). Many researchers (Adler \& Gundersen, 2007; Gregory et al., 2009; Schein, 1990) discuss, common behaviors, honor, interests, and attitudes of people vary extensively between countries because the national culture effectively forms essential capabilities and behavior patterns for their residents (Hatch \& Schultz, 2004).

Numerous national and international organizations provide guidebook for their workers with explanations of organization ethic and culture standards, strategy and value descriptions, and other elements to run such orientations (Silverthorne, 2004). Recent results (Gregory et al., 2009; Silverthorne, 2004) state that, there is an intensive association between national and organization cultures; however, the kind of relationships differs depending on countries, especially in terms of developed and developing countries (Gregory et al., 2009; Silverthorne, 2004). With all these, the experience shows that the national culture is stronger than organizational culture (Henri, 2006; Maier, 1999). 
Adler and Gundersen (2007) and Maier (1999) discusses that, it seems that workers resist a company's culture if it is in opposite to their own national culture because the differences in culture are expressively stronger among employees working within international companies than employees working in companies located in their own countries (Henri, 2006; Maier, 1999). The most interesting point is that most of the successful companies such as IKEA, Toyota, and McDonalds are performing cross-culture production in different countries (Gregory et al., 2009).

Based on the above studies, we try to answer the following research question: What positive and negative impact does the use of social media have in the organizational culture of a company in a country without democratic national culture?

\subsection{Methodology}

The study of the effects of social media in the organizational culture of companies in a country without democratic national culture includes a set of complex personal and social processes, so we designed a research with an inductive approach through primarily qualitative data. The method of data collection was individual interviews of managers from a large company in a non-democratic country. We chose Islamic Republic of Iran (Iran) as a country without democratic national culture. Although Iranian Regime is based on democratic context where people participate in an election for selecting a President, Parliament members and City Council representatives, Iranian policies are still working based on the nondemocratic traditional context where the law system changes depending on each situation (Aras, 2001).

The selected company belongs to heavy manufacturing industries of Iran which is particularly important in supplying items and economic processes. We chose this company for its representation in different ages of Iranian social and political changes, its large amount of employees $(3,500)$, its complex organizational structure, and its wide variety of types of managers according to their education, experience, geographical area, and age.

In order to answer our research question, we decided to collect data from one CEO and five middle managers from the selected Iranian company. Due to these managers being scattered across the country, we decided to conduct interviews by online video conference (Skype). This allowed us to record the interviews and to analyze them from different points of view using the original source. Due to the complexity of the analyzing process, 
we developed a protocol as a conceptual guide on data collected during the interview, with a semi-structured scheme, which allowed participants to express their views in their own words and for us to develop a keen understanding of the topic of interest (Creswell, 2007).

We decided to design the same protocol for the CEO and five middle managers, allowing the interviewer to expand, cut, or even add other potential questions during the interviews. To use the same protocol for all managers avoided bias and also extracted arguments from different points of view of the same phenomenon. We categorized content into four sections. The first one focuses on the gap between social media and leadership context changing in non-democratic countries, based mainly on the works of Ghannam (2011), Keser et al. (2011), Danju et al. (2013), and Brungardt (1997) which aims to understand how social media impacts on transiting of autocracy leadership context to democracy leadership context. The main keywords of these sections are: 1) Leadership style changing, 2) Interaction, 3) Achievement and effectiveness, 4) Security, 5) Inclusion and belonging. The second section centers on the gap between social media and organizational change. From the results of Auger (2013), Taki and Coretti (2013), MacIntosh and Doherty (2010), and Barney (1986) which aim to understand how social media, as new technology development, impacts on the organizational culture in non-democratic countries. The keywords for this section are: 1) Organizational Change and Resistance, 2) Radical and incremental change, 3) Capacity for Change. The third section focuses on the gap between social media and communication context changing which is extracted from Warren et al. (2014), Lund (2003), Riketta (2008), and Creed and Zutshi (2012). This section aims to understand how the impact of social media in communications has changed among leaders, senior managers and employees in the organization. Its keywords are as follows: 1) Transparency, 2) Satisfaction, 3) Collaboration, 4) Self-efficacy, 5) motivation.

The final section centers on the gap between social media and changes in organizational behavior based on the works of Ardichvili et al. (2006), Schein (1990), and Silverthorne (2004) which aims to understand how social media negatively and positively impacts the organizational culture and the behavior of employees in a non-democratic country. The keywords for this section are: 1) Organizational Commitment 2) Team Working. 
In order to analyze collected data, we decided to use MAXQDA, qualitative data analysis software which, allows us to reduce collected data by codes and categories. Moreover, MAXQDA has a huge number of functions to find out different relationships among codes and categories. The process of coding had two steps: the first one was based on a code list extracted from the literature review; the second one followed an inductive approach where we updated the initial code list whilst we were reading and encoding the collected data. We also defined some variables in order to classify the interviews based on gender, age, level of education, work experience (years and countries), and position (CEO or middle managers). These variables make it much easier to deal with multilingual opinions and associations, and provide much better scope than just a traditional encoding system.

The initial code has 7 codes: Social Media Impacts (to identify positive and negative impacts of social media on organizational processes), Organizational Change (to determine how social media changes organization), Leadership (to seek what changes have been impacted on leadership styles for managers due to social media), Country Context (to identify the influence of national culture into the organizational culture), Communication Processes (to determine how managers use social media in order to communicate themselves), Collaboration (to seek new ways to work in organizations using social media) and Organizational Behaviors (to identify the changes of other behaviors in the organization). It's important to highlight that the code Organizational Behavior refers to all organizational behaviors which are not included in the previous codes (e.g. Leadership and Communication). After the first step of encoding, we started to encode following an inductive approach, which added new codes: Interaction (to find new ways of interaction and sharing of responsibilities) and security (to evaluate job security and even the entire security of the organization), and sub-codes. For example, the code Organizational behavior has 3 sub-codes: Satisfaction, Stress and Commitment. Or, the code Collaboration has 2 sub-codes: Team,-working and Knowledge-sharing. We needed a lot of time for the second step of encoding because each time we detected a new code or sub-code, we had to recode the previous interviews in order to ensure that we had considered the same codes and sub-codes in all interviews.

After the process of encoding, the following step was to analyze the relationships between codes and sub-codes in order to emerge no visible associations. We apply multiple methods by MAXQDA to extract and 
expose the fundamental relationships between concepts: code matrices (co-occurrence between codes) and interview-code matrices (the number of times that a code appears in an interview). According to Silver and Lewins (2012), these associations can provide guidelines for relative concepts to exhibit how some concepts shape the particular decryption of a phenomenon. Therefore, based on the MAXQDA guidelines, we prepare co-occurrence definitions as follows: two codes are coding citations by overlapping, within andlor hit each other somehow, or either coding the same citation accurately. Therefore, two codes which, make a cooccurrence in the context are two secrets that are correlated in some way. In fact, a co-occurrence between codes recognizes multiplicity and intensive associations between conceptual factors in order to extract their role in creating a phenomenon.

\subsection{Results and Discussion}

We have divided the main results of research in 3 categories: leadership, communication and collaboration. In each one, we discuss the positive and negative impacts of social media in organizational behaviors in nondemocratic countries from the point of view the Hofstede cultural dimensions (Hofstede, 1994) and Hofstede Centre cross cultural analysis.

\subsection{Leadership}

The literature shows a lack of standard methods for evaluating the relationship between national and organizational culture. Among all possible points of view, we decided to analyze our results from Hofstede cultural theory (Hofstede, 1994) because of its strong explanatory power in such social phenomena in terms of behavior, style and hierarchy. Ghannam (2011), Danju et al. (2013), Kneissl (2011), and Auger (2013) Show an increasing attention to the strategic aspect of social media which highlights that the influence of the national culture on the leadership context and the organizational culture in non-democratic countries. Our results shows that the relationship between country and leadership context is much higher than other studied constructed. These results are in line with Gregory et al. (2009) and Silverthorne (2004) which also applied Hofstede cultural dimension model to suggest that there is an intensive association between country culture and organizational culture; however, the kind of the relationship differs based on the country context (Silverthorne, 2004). It is difficult to predict the specific effects that the Iranian culture has on work characteristics. Nevertheless, it is beneficial to 
suggest an exploratory proposition that mainly forecasts these associations.

Proposition 1: The leadership context in organizations is influenced by the country's culture context in non-democratic countries.

The majority of developed and democratic countries (e.g. USA) have adopted new forms of management to enhance participation of all organizational members in achieving goals (Minkov and Hofstede, 2012; Silverthorne, 2004). While Middle East countries still pursue hierarchical contexts (McSweeney, 2002; Minkov and Hofstede, 2012). According to the Hofstade Centre (2015), scores of Iranian power distance is 58, much higher than other countries such as the USA which power distance score is 40. Danju et al. (2013), Ghannam (2011), Taki and Coretti (2013), and Kneissl (2011) state that the use of social media accelerate the democratization of behaviors inside of organizations, because it forces to adopt new forms of management against organizational resistance in nondemocratic countries. The results of our interviews support the idea that Iranian companies, despite their willingness to new forms of management, preserve the traditional organization hierarchy. The higher score of association between traditions and transformational leadership support the Hofstede's dimension in power distance; According to Hofstede Centre (2015), cultures with high scores in power distance tend to be more hierarchical. From interviews, it seems that the CEO and middle managers are not interested to distribute power among their subordinates because there is a fear of losing control. In other words, the attitude of CEO and middle managers about equality between managers and employees is not accepted. As CEO and one middle managers said:

CEO: In a country such as Iran, It is not possible to adopt new management systems in a short period of time. In initiating this, culture capacities should be acknowledged before adoption. This work needs collective thinking That is because any mistake could turn into a disaster.

Middle Manager: However, I believe leadership context should develop based on modern theories, but simultaneously employees and other members also should increase their knowledge towards this change. We experienced a greater number of disintegration in companies and even industries because of incorrect changes.

Based on Hofstede's cultural analysis (Hofstede Centre, 2015), Iran is a country with hierarchical culture. It means Iranian people accept they have a place and no need for additional justification. Iranian organizations 
reflect inherent inequalities and employees expect to be ordered what to do (McSweeney, 2002; Minkov and Hofstede, 2012; Silverthorne, 2004). CEO is the main decision maker and the centralization is the core element in the culture of their companies (Hofstede, 1994). However, our findings show that managers and leaders of the company gradually changed their leadership context, preferring to distribute their responsibilities to lower managers but simultaneously keeping organizational hierarchical and position of power. In addition, the results also show that the CEO and middle managers of a company discourage employees and lower managers from participating in the main decision making while they claim that they are interested to adopt modern management. Therefore this paradox forced us to suggest a proposition based on the planar thought of CEO and middle managers.

Proposition 2: Managers resist organizational change in accordance with new forms of management context to save organizational hierarchical in the non-democratic country context.

Based on the results of the Hofstade center (2015) about the Individualism/collectivism measurement, the iranian score of individualism is 41 which results in a collectivistic society. Our findings show a different result from the Hofstede cultural analysis. According to the results, both CEO and middle managers propose the necessity to keep their power based on the transactional leadership context, although they have a tendency to participative management. We can see these ideas when CEO and middle managers says that they prefer to keep organizational hierarchy to maintain control (Auger, 2013; Brungardt, 1997). The degree of association between transactional leadership and modernity shows this paradox more clearly. The combination of Iran power distance (58) and Iran Individualism/collectivism (41) support this idea that Iranian managers tend to have modernity behavior, but keep their job's control and power in the same way as in the traditional contexts. So, we can consider that Iranian managers do not accept the equality of organization members. This is evidenced by a frank stress on unequal rights in all aspects of Iranian organizations. While USA organizations used to build hierarchies to make it convenient for managers to rely on teams and employees for their skills and creativeness (McSweeney, 2002; Minkov and Hofstede, 2012), Iranian organizations used to establish hierarchies to control employees in order to avoid review of their own specified responsibilities. Nevertheless, from the results, we have identified that the use of social media impacts on leadership context. Both 
CEO and middle managers believe these changes were processing intangibly. Although social media strategies are not yet well developed in the Iranian organizations, we have detected some impacts on organizational behaviors and the leadership context. For example, the CEO stated:

CEO: The modern style of leadership reached in Iran much later than developed countries because there was a lack of culture capability to accept these changes in the Iranian society although social media networks facilitate this process much faster.

Based on the data analysis, the co-occurrences between variables show that there is a positive association between leadership context and social media impact. Danju et al (2013), Ghannam (2011), and Kneissl (2011) show that there is a movement on the leadership context transition from autocracy to democracy since the social media appeared in developing countries; However, this movement can be seen as the result of Arab Spring in some countries, which is mentioned by CEO middle managers during interviews, but in the case of Iran, the results show that there was an earlier leadership changing within Iranian companies since social media appeared. Some middle managers believe that this movement incrementally changes the leadership context while the CEO stated that the kind of leadership context radically changed due the appearance of technology advancement. The degree of co-occurrence between social media positive impact and transformational leadership is significantly higher than transactional leadership. Fransen et al. (2015) state that, leaders would not work in social vacuums, but with the advent of social media they would prefer to make relationships in an online interactive network with their employees and managers. This idea is also supported by Danju et al. (2013) and Kneissl (2011). Based on the above discussion, we suggest a proposition based on the effect of social media in the transformation of leadership context.

Proposition 3: The use of social media in companies in non-democratic countries helps to move from transactional to transformational leadership.

\subsection{Communication}

According to the Hofstade center (2015), the Iranian low score in longterm orientation (14) specifies that Iran involves of an intensive tendency to normative culture. There is a high concern for persons in such societies in making the complete truth; because they are so disarranged and confused in their thinking (Hofstede, 1994; Silverthorne, 2004). They 
represent a minor tendency to save for the future because they excessively admire traditions, and an emphasis on attaining fast consequences (Auger, 2013; McSweeney, 2002; Minkov and Hofstede, 2012). While several democratic and developed countries such as the USA also are in a low score in possibility to examine data to accept absolute truth and the culture should represent low practicable, but in reality, these societies are very pragmatic (Minkov and Hofstede, 2012). Our results support that traditional views are more capable than modernism in Iranian organizational culture. Despite that the middle managers and CEO were strongly interested to adopt modern management contexts in the organization; they still follow the core ideas of their tradition. As all of them mention, Iranian society cannot adopt new changes in a short period of time because the removal of staff from the traditional system is very complicated and requires a long-term plan. Our results support that the lack of cultural capacities for change in non-democratic countries rise up organizational resistance. Based on this issue, we suggest a proposition to create a new discussion about the culture capability and the social media development in organizations in non-democratic countries.

Proposition 4: The lack of culture capabilities in non-democratic countries resist organizations to move from traditions to modernism.

Transparency on the organizations is more appreciated in Western than in Estern countries (Gregory et al., 2009; Lund, 2003). Social media has been evaluated as a lever in the increasing transparency in the workplace and society. So, it can come in the form of more ethical behavior, better organisational communication patterns, and the avoidance of discriminatory Creed and Zutshi (2012). Our results support that social media increase transparency in the workplace; however, CEO and middle managers believe that the use of social media also has a negative impact on organizational communication and also in some processes. Our analysis of the interviews shows that there is a high co-occurrence degree between the negative impact of social media and the transparency. CEO and middle managers pointed that social media give transparency but that the lack of democratic culture in the use of social media lead this process to deviance behaviors. Communication change in the Iranian companies made negative effects in the transparency of individuals, and subsequently on the functioning of organizations. The final result is the appearance of a conflict Gregory et al. (2009); Lund (2003). Our results are in the line of Creed and Zutshi (2012) which identified that the increase of transparency could increase the intentional abuse in some situations. Moreover, the use 
of social media could magnify these behaviors. For example, social media tools increase rumors in the organization which create a convulsive work space for the CEO and middle managers. CEO and one middle manager stated that:

CEO: However we believe social media usage is increasing efficiency in work communication, but it also can create a hostile environment of rumors and gossip In which all of them are against CEO and managers.

Middle Manager: Social media around the world caused organizations to enter into a new interactive environment where staffs are sharing their ideas and knowledge, but in Iranian companies, social media is the best tool to accelerate rumors made up by employees.

Based on the above discussion, we suggest the following proposition about the negative effects of the use of social media on transparency.

Proposition 5: The use of social media inside of organizations has negative impact on transparency, creating deviance behaviors in nondemocratic countries.

Stress was another negative impact of the social media inside of the Iranian company's. Our results show that there is a high association between negative impact of social media and stress. Interviewees stated that by the use of social media inside of an organization, a stressful environment arose for the CEO and managers towards organizational control. They stated that easy access to social media networks by the introduction of smartphones and mobile networks which enable employees to communicate with others within working hours has a negative impact on work quality. The use of social media inside of organizations increases stress levels for managers because it makes control more difficult. As Creed and Zutshi (2012); Gregory et al. (2009); Lund (2003) stated that accordingly the use of social media increase organizational stress to develop new changes based on the organizational culture. However, CEO and middle managers believe social media usage must be balanced by making new policy to adopt a more ethical and efficient work environment. Based on the discussion above, we developed a proposition to suggest how social media increase stress inside of organizations in nondemocratic countries.

Proposition 6: The use of social media increases stress levels in the organizational environment of managers in non-democratic countries. 


\subsection{Collaboration}

Finally, according to the Hofstede center (2015), the results in collectivism of the Hofstede cultural analysis indicates Iran is a collectivistic society. Basically collectivism culture reflects commitment and relationship to the workplace, family, group and members in long-term (Arpaci \& Baloglu, 2016; Silverthorne, 2004). In fact, collectivist values loyalty and everyone take responsibility for its group, task and colleagues.

Organizational members in a collectivistic society are observed in an moral term where all of them are linked to each other as a family (McSweeney, 2002, Minkov and Hofstede, 2012). In such society, sharing information is very popular and everyone would like to notify others from news, events and other cases.

Some results Arpaci and Baloglu (2016) indicate that cultural collectivism has a positive impact on information technology with regard to sharing knowledge and information. Our results also support that social media facilitates and increases knowledge sharing among organizational members in collectivistic country such Iran. The association between the social media positive impact and knowledge is quietly high which indicate that employees and managers adhere use of social media to share knowledge regard to organization development. However, the CEO and the middle managers frequently stated that the culture of use of social media inside of the organization is not well developed. In the case of knowledge sharing, they believe social media enhances the organization knowledge. As Iran is collectivistic society, employees of Iranian company are developing themselves by the newest knowledge and international changes not only for personal use but also they share their ideas and knowledge among their colleagues. As a result, we suggest the following proposition:

Proposition 7: The use of social media helps knowledge sharing regard to collaboration inside of organization in non-democratic countries.

The easy making of socialization in an organizational workplace, easy use and special friendly features of social media, attract employees to pursue social media potentialities in their workplace and ignore the limited policies of company resistance towards new information technology enhancement (Arpaci \& Baloglu, 2016; Georgescu \& Popescul, 2015). Usually, employees who are strongly connected to social media networks would not keep and conceal what they gained from available resources. Therefore, employees often share their ideas with each other to increase 
job quality. However, some studies (Davenport, Bergman, Bergman, \& Fearrington, 2014; Hawk, ter Bogt, van den Eijnden, \& Nelemans, 2015; Marshall, Lefringhausen, \& Ferenczi, 2015) stated that the use of social media inside of organizations increases narcissism among employees which cause team-working obstacles because of self-exhibition. Our findings suggest some interesting differences in organizational behaviors. As we mentioned above, narcissism is a stronger indicator of social media networks, because these kinds of networks enable narcissists to make friends based on their interest and attitudes. However, our results show that the social media has a positive impact on the team-work inside of an organization. The interesting paradox that has been found from data collected is that, managers believe social media causes workplace stress while they stated that team-work increased inside of an organization through the advent of social media.

This conflict shows that in the use of social media, managers experience a more complex environment whilst increasing employees' collectivism. The CEO and middle managers stated that employees have created small groups for suggesting new ideas to their department managers and they react to all decision made by managers whilst before the workplace was defined with specified responsibilities and each employees only work to perform its defined task. The CEO and middle managers also stated that this kind of collectivism sometimes faced the company with labor strikes, but globally the advantages of team-working made them better in their work achievement. Therefore we suggest a proposition based on the discussion above as follows:

Proposition 8: The use of social media helps employees to work as a team towards work achievement in non-democratic countries.

\subsection{Conclusion}

This research tried to answer the research question: What positive and negative impacts does the use of social media have in the organizational culture of a company in a country without democratic national culture? In order to answer this question, we developed a model based on the existing literature reviews about the processes of social media impacts on developing country and societies by focusing on recent uprisings in the Middle East and North African countries (Arab Spring). We also included the Hofstede's cultural dimensions analysis, as well as some organizational behaviors. We followed an inductive approach with qualitative methods based on semi-structured interviews to one CEO and 
five middle managers from an international company in Iran. The results were divided in three main areas: leadership context, communication and collaboration.

Our results suggest that the leadership context is generally influenced by the country's culture in non-democratic countries. Based on this, managers resist organizational change with new forms of management to keep the current organizational hierarchy.

The use of social media inside of these organizations accelerates the democratization which positively impacts on leadership transforming from transactional to transformatonal context. Because of the changes in communication technology through the use of social media, our results suggest that the use of social media has negatively impacted on the transparency which, has created deviance in behaviors inside of organizations from employees in non-democratic countries. Furthermore, the use of social media increase stress in managers within this kind of organization. From another point of view, social media helps knowledge sharing among employees with regard to enhancing collaboration in nondemocratic countries. Finally, the use of social media also increases employees' collectivism which, indirectly also increase team-working skills towards their work achievement.

The use of social media builds a bridge between national and organizational culture; however, there is a lack of culture capacity in the use of social media inside of organizations, but it has impressive positive impacts on the main organizational culture context.

Despite these benefits, some methodological limitations remain. The result of this research reveals several suggestions worthy for future studies. First of all, it suggests further seeking how social media reconstructs the type of leadership in organizations and rising up the needs for participative management in the traditional spaces of non-democratic countries. This research suggests that the change in communication technology impacts on organizational culture where the transparency is one of the most effective elements. Thus it would be helpful to examine how social media change the construct of transparency inside of organizations and how is translated into a context of opportunity or vulnerability for organizations in non-democratic countries. However, the country culture is stronger than organizational culture but the results of this research suggest that social media simultaneously impact on both contexts by mobilizations for civic engagement. The reason for this ideology, it seems, is that the power 
beyond of social media increases democratization in all aspects of societies in non-democratic countries. At the current, this research opens a new view of power of social media in non-democratic countries that has been out of focuses of scholars.

\section{References}

Adler, N. J., and Gundersen, A. (2007) International dimensions of organizational behavior, 5th edn., Ohio: Thomson Higher Education.

Aras, B. (2001) 'Transformation of the iranian political system: Towards a new model?', Middle East, Vol. 5 No. 3, p.13.

Ardichvili, A., Maurer, M., Li, W., Wentling, T., and Stuedemann, R. (2006) 'Cultural influences on knowledge sharing through online communities of practice', Journal of knowledge management, Vol. 10 No. 1, pp. 94-107.

Arpaci, I., and Baloglu, M. (2016) 'The impact of cultural collectivism on knowledge sharing among information technology majoring undergraduates', Computers in Human Behavior, Vol. 56 No. 1, pp. 6571.

Auger, G. A. (2013) 'Fostering democracy through social media: Evaluating diametrically opposed nonprofit advocacy organizations' use of facebook, twitter, and YouTube', Public Relations Review, Vol. 39 No. 4, pp. 369-376.

Barney, J. B. (1986) 'Organizational culture: can it be a source of sustained competitive advantage?', Academy of management review, Vol. 11 No. 3, pp. 656-665.

Brungardt, C. (1997) 'The making of leaders: A review of the research in leadership development and education', Journal of Leadership and Organizational Studies, Vol. 3 No. 3, pp. 81-95.

Burke, W. W. (1994) 'Diagnostic models for organization development', Diagnosis for organizational change: Methods and models, pp. 53-84.

Contreras, R.B. (2011) 'Examining the Context in Qualitative Analysis: The Role of the Co-Occurrence Tool in ATLAS ti', Newsletter, p.1-2. Creed, A., and Zutshi, A. (2012) 'Social media: does it generate the continuum of transparency in organizations?', in Reiman, C. (Eds), Public Interest and Private Rights in Social Media, Oxford Cambridge New Delhi, Oxford, pp. 129-144.

Creswell, J.W. (2012) Qualitative inquiry and research design: Choosing among five approaches, 3rd edn., London: Sage. 
Danju, I., Maasoglu, Y., and Maasoglu, N. (2013) 'From autocracy to democracy: The impact of social media on the transformation process in north Africa and middle east', Procedia-Social and Behavioral Sciences, Vol. 81 No. 1, pp. 678-681.

Davenport, S. W., Bergman, S. M., Bergman, J. Z., and Fearrington, M. E. (2014) 'Twitter versus facebook: Exploring the role of narcissism in the motives and usage of different social media platforms', Computers in Human Behavior, Vol. 32 No. 1, pp. 212-220.

Ellison, N. B., et al. (2007) 'Social network sites: Definition, history, and scholarship', Journal of Computer-Mediated Communication, Vol. 13 No. 1, pp. 210-230.

Fransen, K., Van Puyenbroeck, S., Loughead, T. M., Vanbeselaere, N., De Cuyper, B., Broek, G. V., and Boen, F. (2015) 'Who takes the lead? social network analysis as a pioneering tool to investigate shared leadership within sports teams', Social Networks, Vol. 43 No. 1, pp. 28-38.

Georgescu, M., and Popescul, D. (2015) 'Social media-the new paradigm of collaboration and communication for business environment', Procedia Economics and Finance, Vol. 20 No. 1, pp. 277-282.

Ghannam, J. (2011) 'Social media in the arab world: Leading up to the uprisings of 2011', Center for international media assistance, Vol. 3 No.1, pp.1-44.

Gil de Zúñiga, H., Jung, N., and Valenzuela, S. (2012) 'Social media use for news and individuals' social capital, civic engagement and political participation'. Journal of Computer-Mediated Communication, Vol. 17 No. 3, pp. 319-336.

Gregory, B. T., Harris, S. G., Armenakis, A. A., and Shook, C. L. (2009) 'Organizational culture and effectiveness: A study of values, attitudes, and organizational outcomes', Journal of Business Research, Vol. 62 No. 7, pp. 673-679.

Hatch, M. J., and Schultz, M. (2004) Organizational identity: A reader, New York: Oxford University Press.

Hawk, S. T., ter Bogt, T. F., van den Eijnden, R. J., and Nelemans, S. A. (2015) 'Too little power, too much information! power, narcissism, and adolescents' disclosures on social networking sites'. Computers in Human Behavior, Vol. 52 No. 1, pp. 72-80.

Henri, J. F. (2006) 'Organizational culture and performance measurement systems', Accounting, organizations and society, Vol. 31 No. 1, pp. 77103.

Hofstede, G. (1994) 'The business of international business is culture', International business review, Vol. 3 No. 1, pp. 1-14. 
Jin, C. (2013) 'The perspective of a revised tram on social capital building: The case of facebook usage', Information and Management, Vol. 50 No. 4, pp. 162-168.

Kaplan, A. M., and Haenlein, M. (2010) 'Users of the world, unite! the challenges and opportunities of social media', Business horizons, Vol, 53 No. 1, pp. 59-68.

Keser, H., Uzunboylu, H., and Ozdamli, F. (2011) 'The trends in technology supported collaborative learning studies in 21 st century', World Journal on Educational Technology, Vol. 3 No. 2, pp. 103-119.

Kneissl, K. (2011) 'Elements for a scientific analysis of the Arab revolutions in spring 2011', ÖAW, Vol. 21, No. 1, pp. 1-19.

Lund, D. B. (2003) 'Organizational culture and job satisfaction', Journal of business and industrial marketing, Vol. 18 No. 3, pp. 219-236.

MacIntosh, E. W., and Doherty, A. (2010) 'The influence of organizational culture on job satisfaction and intention to leave', Sport Management Review, Vol. 13 No. 2, pp. 106-117.

Maier, M. (1999) 'On the gendered substructure of organization: Dimensions and dilemmas of corporate masculinity', Handbook of gender and work, pp. 69-94.

Marshall, T. C., Lefringhausen, K., and Ferenczi, N. (2015) 'The big five, self-esteem, and narcissism as predictors of the topics people write about in facebook status updates', Personality and Individual Differences, Vol. 85 No. 1, pp. 35-40.

McShane, S., and Travaglione, A. (2007) Organisational Behaviour on the Pacific Rim, 2nd edn., Ohio: McGraw Hill Higher Education.

McSweeney, B., (2002) 'Hofstede's model of national cultural differences and their consequences: A triumph of faith-a failure of analysis', Human relations, Vol. 55 No. 1, pp. 89-118.

Minkov, M. and Hofstede, G. (2012) Cross-cultural analysis: the science and art of comparing the world's modern societies and their cultures, London: Sage.

Poorkarimi, M., et al. (2013) 'Why and how effect arts education in the perspective of educational psychology', Global Journal of Arts Education, Vol. 2 No. 1, pp. 7-10.

Riketta, M. (2008) 'The causal relation between job attitudes and performance: a meta-analysis of panel studies'. Journal of Applied Psychology, Vol. 93 No. 2, p. 472.

Schein, E. H. (1990) 'Organizational culture', American Psychological Association, Vol. 45 No. 2, P. 109.

Schiuma, G., Vuori, V., and Okkonen, J. (2012) 'Knowledge sharing motivational factors of using an intra-organizational social media 
platform', Journal of Knowledge Management, Vol. 16 No. 4, pp. 592603.

Shirky, C. (2011) 'The political power of social media', Foreign affairs, Vol. 90 No. 1, pp. 28-41.

Silverthorne, C. (2004) 'The impact of organizational culture and personorganization fit on organizational commitment and job satisfaction in taiwan', Leadership and Organization Development Journal, Vol. 25 No. 7, pp. 592-599.

Taki, M., and Coretti, L. (2013) 'The role of social media in Arab uprisings-past and present', Westminster Papers in Communication and Culture, Vol. 5 No. 2.

The Hofstede Centre. [online] http://geert-hofstede.com/united-states.html. (Accessed 17 November 2015).

Warren, A. M., Sulaiman, A., and Jaafar, N. I. (2014) 'Social media effects on fostering online civic engagement and building citizen trust and trust in institutions', Government Information Quarterly, Vol. 31 No. 2, pp. 291-301.

Zukin, C., Keeter, S., Andolina, M., Jenkins, K., and Carpini, M. X. D. (2006) A new engagement?: Political participation, civic life, and the changing American citizen, New York: Oxford University Press. 